\title{
Determination of an Extrusion Machine Performance Based on the Working Field of the Extruder Die
}

\author{
VALERIU V. JINESCU*, MIHAIL JUGANARU, COSMIN JINESCU*, NICOLETA SPOREA \\ Politehnica University of Bucharest, Mechanics and Mechatronics Faculty, Industrial Process Equipment Department, \\ 313 Splaiul Independentei, 060042, Bucharest, Romania
}

\begin{abstract}
Some inventions along with theoretical and experimental research made it possible to increase the output of a thermally homogeneous melt provided by the screw. However, the quality of the extruded product depends on some specific features of the extrusion die and to a large extent on the rheological behavior (viscous and elastic) of the polymer melt. The mismatch between the design of the screwcylinder subassembly and the design of the extrusion die results in products with relatively short service life. The present paper has drawn up the working field of the extruder die and adjusted it based on the limitations imposed by the screw-cylinder subassembly, namely: - the maximum output rate that ensures the required thermal homogeneity of the melt; - the maximum output at which the heating system on the barrel (and possibly the screw) ensures the extrusion temperature; - the minimum economic output corresponding to the diameter of the screw. The working field of some extrusion dies for blown films of the following polymers have been plotted: polypropylene, low density polyethylene, high density polyethylene and ethylene vinyl acetate.
\end{abstract}

Keywords: extrusion of polymeric materials, extrusion die, working field of extrusion die, operating characteristics of extrusion die and screw

\section{Introduction}

In their operation polymer processing machines thermally pollute the environment, which results, among other things, in relatively low energy efficiency of machines operating in a polytropic mode.

On the other hand, in the case of plastics extrusion, the mismatch between the design of the screwcylinder subassembly and the construction of the extrusion die results in products with internal stresses and inhomogeneous cross-section. The lifetime of these products is relatively short. In the case of pipes, for example, fracturing before the prescribed service life can lead to the environmental pollution caused by the substances flowing through.

Therefore, it is necessary to analyze the working field of the extrusion die considering the parameters of the extrusion process, the behavior of the polymer melt, the conditions imposed by the quality of the product and some economic considerations.

Extrusion machines have been improved particularly after 1953, when the first in-depth theoretical analyses of the extrusion process were published [1-10]. The main objective was to design and manufacture the extruder screw in such a way as to ensure the highest possible output of a thermally homogeneous melt.

There were created spiral threaded screw barrier and then consequently intensive mixing zones on the screw [11]. To increase the output, grooved zones were provided on the cylinder in the feed zone, which by increasing the friction coefficient between the polymer granules and the cylinder resulted in increased machine output [12].

Experimental and theoretical investigations in relation to the machine output, calculation relations established for the output [13;14], design solutions and relations corresponding to zones of intense homogenization [15-17], as well as those related to the establishment of thermal inhomogeneity and melt temperature variation in the screw channel [18] led to the increase of the screw potential output.

*email:vvjinescu@yahoo.com,cosmin.jinescu@yahoo.com 
To optimize the extrusion process, initially the machine optimization diagram was plotted upon output-pressure coordinates at the outlet of the extruder screw. Subsequently, the working field of the extruder die was defined and plotted on the output-pressure coordinates at the extruder die inlet. The ensuing argumentation puts forth an improved, completed version of how to define the working field of the extruder die.

\section{Extruder die working field and micro working field}

In the extruder die the melt pressure decreases from $p_{e}$, at the inlet of the extruder die, to value $p_{f}$ in the end section of the die. Pressure $p_{f}$ may be greater than or equal to the atmospheric pressure, $p_{0}$; this depends on the geometry of the extrusion die, flow velocity and the elastic properties of the melt. The melt temperature at the extrusion die is taken to be constant and equal to the extrusion temperature, $T_{e}$, characteristic of each polymer.

The working field of the extrusion die (in the half-plane delimited by the $G_{m}$ coordinates - flowrate or mass output - and pressure $p_{e}$ ) is obtained inside the contour determined by the intersection of the following curves (Figure 1)

1 - minimum pressure curve $p_{e, \text { min }}(T)$, at a given working temperature, conditioned by the minimum quality accepted for the product

2 - maximum pressure curve, $p_{e, \max }(T)$, at a given working temperature, conditioned by the minimum value adopted for the total efficiency

3 - the characteristic of the die $\left(G_{m}-p_{e}\right)_{3}$ corresponding to the maximum temperature $T_{e, \text { max }}$, at which the extrusion of the respective material can take place

4 - the characteristic of the die $\left(G_{m}-p_{e}\right)_{4}$ corresponding to the minimum temperature, at which the extrusion of the thermoplastic material can take place

5 - maximum allowable output curve, $G_{a d \text {, max }}$, corresponding to the maximum allowable melting speed through the die.

The drawn curves delimit the working field (ABCDEA) of the extrusion die as shown in Figure 1.

The actual working field of the extrusion die (ABCDEA, Figure 1) must be adjusted to consider the following (Figure 2):

- the extrusion die is attached to a cylinder-screw subassembly characterized by a certain value of the inner diameter of cylinder $D(45 ; 63 ; 75 ; 90 ; 100$ etc. $\mathrm{mm})$, which corresponds to a certain minimum economic output $G_{\mathrm{m}, \min } \min ($ curve 6 );

- the construction of the screw-cylinder subassembly ensures a certain maximum output from the viewpoint of the thermal homogeneity of the melt, $G_{\mathrm{m}, \mathrm{om}}$ (curve 7 );

- the heating system of the machine cylinder (and possibly of the screw) makes it possible to attain the extrusion temperature of the melt, $T_{e}$, up to a certain maximum value of the flow, $G_{\mathrm{m}, \mathrm{th}}$ (curve 8 ).

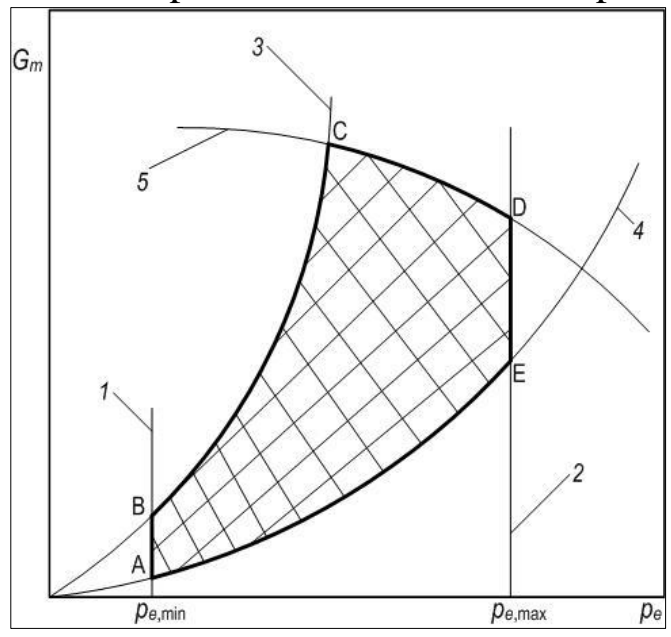

Figure 1. Extrusion die working field (ABCDEA) 
The working field adjusted to suit the limitations imposed by the screw-cylinder subassembly becomes ABCDEFGA in Figure 2.

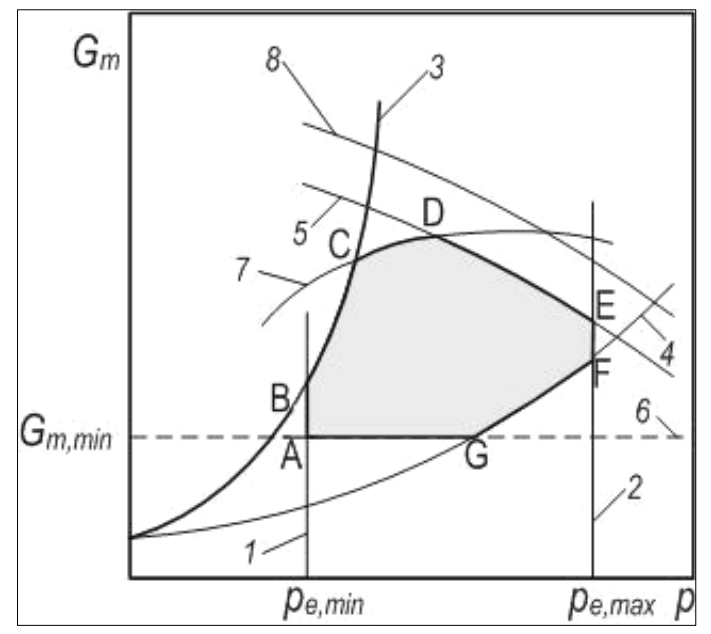

Figure 2. Working field of extrusion die (ABCDEFGA)

with the limitations imposed by the screw-cylinder subassembly

Next, one has to draw the characteristic of the extrusion die $G_{m}\left(p_{e}\right)$ at the extrusion temperature, $T_{e}$, and at temperatures $T_{e}-\Delta T_{e}$ and $T_{e}+\Delta T_{e}$ (Figure 3), where $\Delta T_{e} \leq \Delta T_{a d}$ represents the amplitude of the temperature fluctuation. The allowable amplitude of temperature fluctuation $\Delta T_{a d}$ depends on how the temperature influences the rheological behavior of the thermoplastic melt Materials wherein a significant variation in viscosity occurs at a low temperature variation allow for correspondingly small values of $\Delta T_{a d}$.

Next, the functional characteristics of the screw $\left(G_{m}\left(p_{e}\right)\right)$ are drawn, for several of its rotations $\left(n_{1} ; n_{2} \ldots n_{k}\right)$, as in Figure 4. They must cross the working field of the extrusion die (Figure 5). Otherwise, another screw, or extruder with a different diameter $D$ shall be used (as the case may be, larger or smaller diameters).

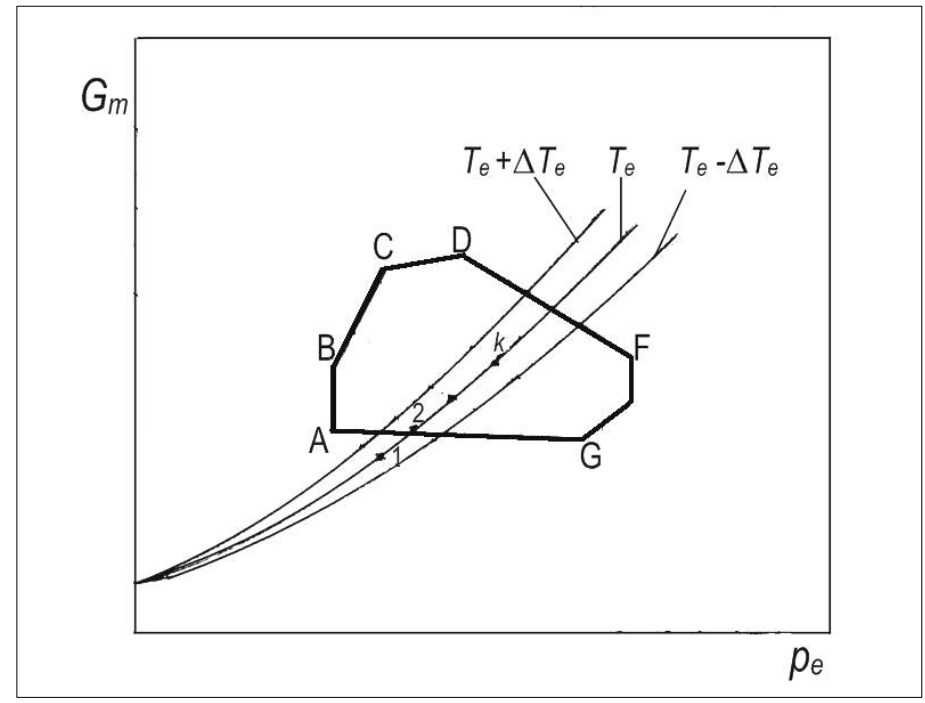

Figure 3. Extrusion die operation diagram 


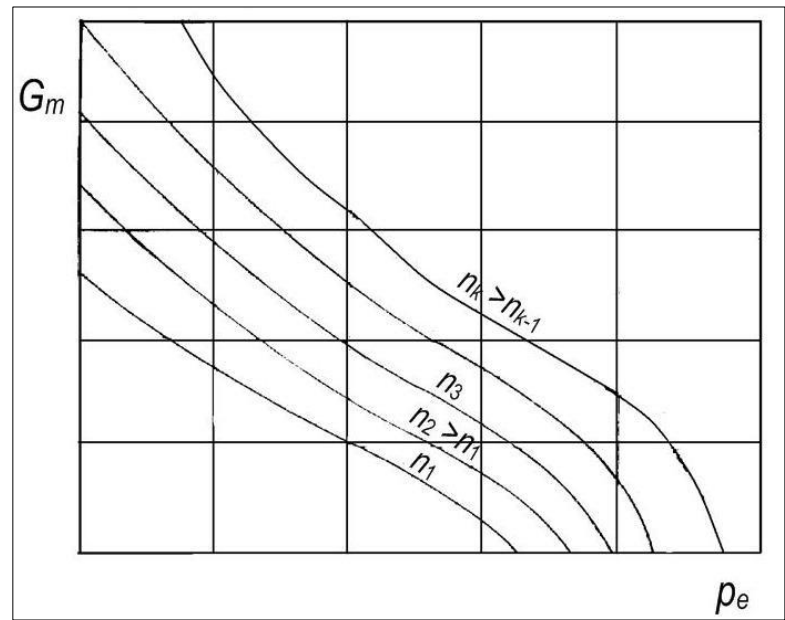

Figure 4. Functional characteristics of the screw at velocities $n_{1} \ldots n_{k}$

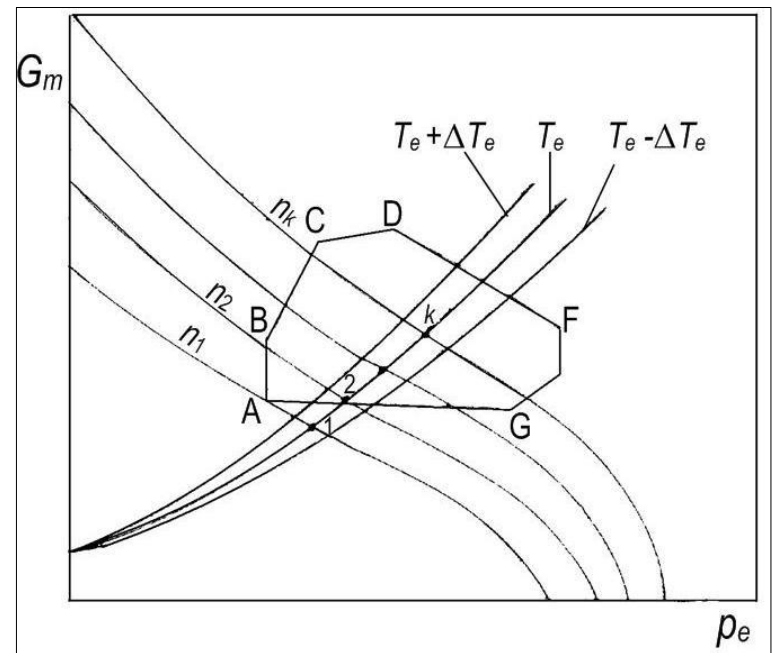

Figure 5. Operation diagram of the screw-extrusion die ensemble

Possible operating points $(1 ; 2 ; \ldots k)$ are obtained. The operating point corresponding to the maximum output $(k)$ is chosen. Intersection points outside the working field of the extrusion die (for example, 1 in Figure 5) either do not ensure the quality of the extruded product or do not provide an economically accessible output.

The output of the extruder is proportional to the bulk density of the granular material in the inlet area of the screw. The bulk density varies randomly between a minimum, $\rho_{v, \text { min }}$, and a maximum value, $\rho_{v, \max } \cdot$

As a result, at a certain speed, $n$, the output provided by the screw, $G_{m}$, (randomly) takes values between the curves corresponding to these two bulk densities (Figure 6). Also, because the melt temperature randomly varies between $T_{e}-\Delta T_{e}$ and $T_{e}-\Delta T_{e}$, basically three characteristics of the extrusion die $G_{m, e x t r, d i e}$ drawn, (Figure 6). 


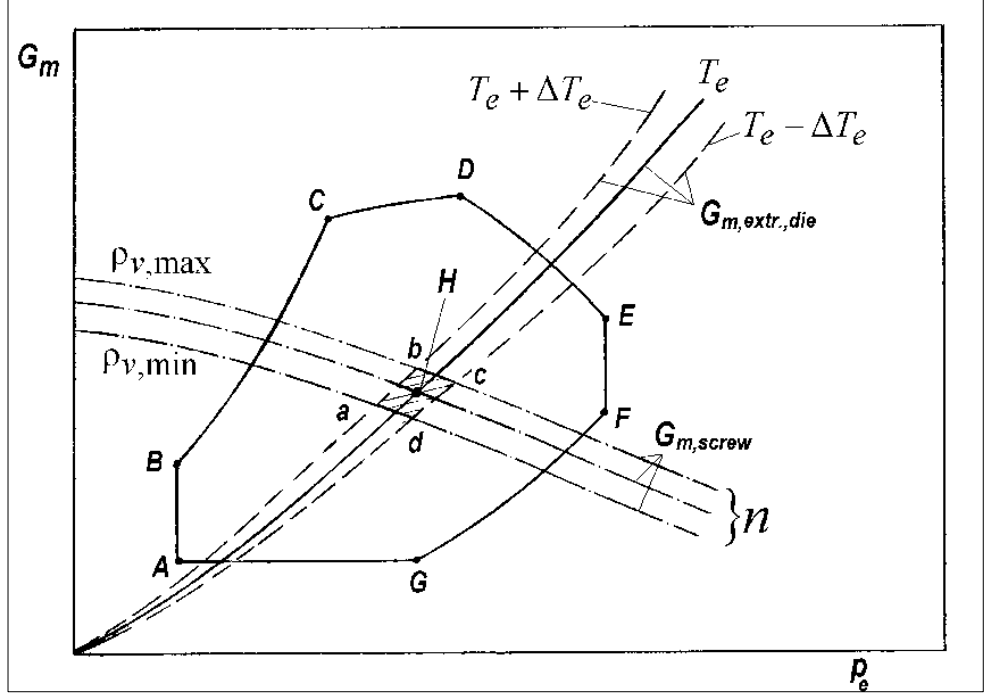

Figure 6. Operating micro-zone abcd for an extruder with a certain screw diameter $D$ at its $n$ velocity

From the intersection of the two groups of extreme curves, the working micro-domain $a b c d$ and the theoretical operating point, $H$, of the screw-extrusion die ensemble are obtained (Figure 6).

\section{Influence of melt viscoelastic behavior on critical parameters}

The shape and dimensions of the working field depend on the rheological behavior of the polymer melt flowing along the path from the extrusion die, at temperature $T_{e}$, under the action of pressure $p_{e}$.

In the final nozzle of the extrusion die, which ensures the shape and dimensions of the finished product, between the melt and the die wall a shear stress $\tau_{p}$ is exerted on the wall, corresponding to a shear strain $\dot{\gamma}_{p}$.

If they become equal to or greater than their critical values

$$
\tau_{p} \geq \tau_{c r} \text { and } \dot{\gamma}_{p} \geq \dot{\gamma}_{c r}
$$

then non-uniformities appear in the product (elastic turbulence, shark skin, etc.) as a manifestation of the elastic behavior of the viscoelastic melt $[19,20]$.

In the case of the non-Newtonian viscous behavior of the melt, given by the Ostwald - de Waele law, there is a nonlinear dependence between the shear stress, $\tau$, and the shear strain $\dot{\gamma}$,

$$
\tau=K_{\tau} \cdot \dot{\gamma}^{v}
$$

wherein $K_{\tau}$ and $v$ are rheological constants at temperature $T_{e}$, whose values for a given polymer depend on temperature and pressure.

In the die, the pressure keeps the melt compressed. Because the melt is viscoelastic, normal stresses $\sigma$ accumulate in it. When leaving the die, in the pressure environment $p_{0}<p_{f}$, stresses $\sigma$ relax, which leads to the swelling of the product (Figure 7). 


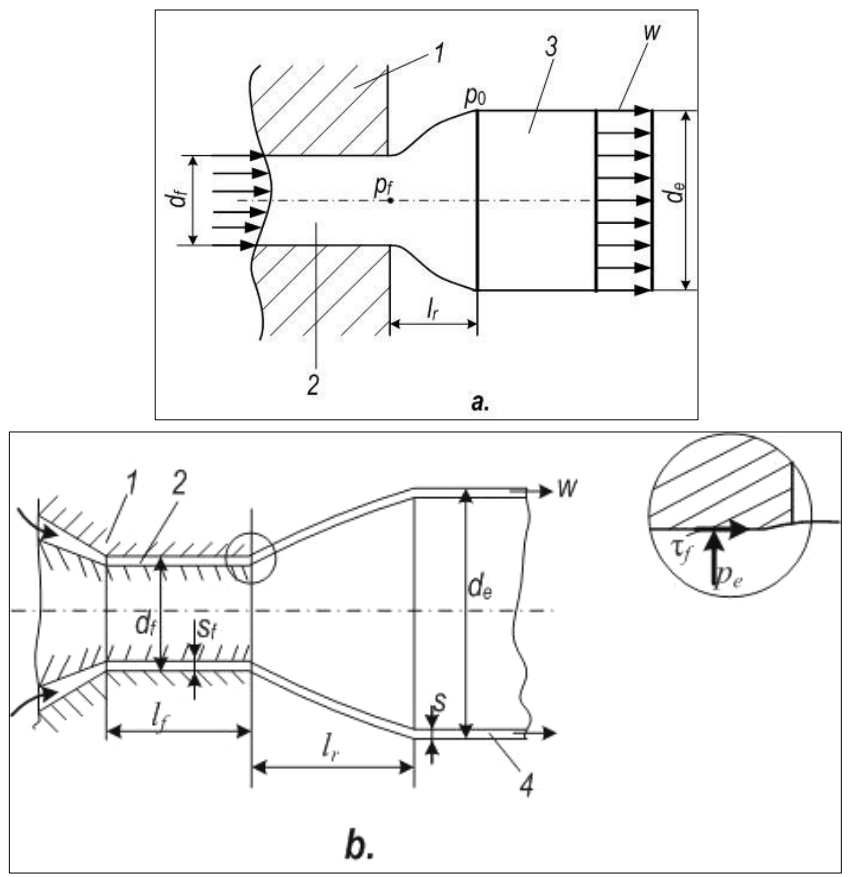

Figure 7. Final zone of the extrusion die for:

$\mathrm{a}$ - wires or bars with circular section; $\mathrm{b}$ - pipe with cylindrical annular section. 1 - die; 2 - melt; 3 - bar or wire; 4 - tubular film

For example, in the case of a product with a section that is:

- cylindrical (bar, wire...), one passes from the melt diameter in the die, $d_{f}$, to the outer diameter of the product $d_{e}>d_{f}$ (Figure 7a)

- cylindrical ring, one passes from the outer diameter $d_{f}$ and thickness $s_{f}$ in the die, to the outer diameter $d_{e}>d_{f}$ and thickness $s<s_{f}$ after covering the distance $l_{r}$, which corresponds to the duration of relaxation.

In both cases, the duration of relaxation of the normal internal stresses of the melt is

$$
t_{r}=l_{r} / w,
$$

where $w$ is the velocity of the product after leaving the die.

As a result of the superposition of the effects of normal stresses, $\sigma$, and the shear stress on the wall, based on the principle of critical energy [49], the following interdependence was established [21]:

$$
\left(\frac{\dot{\gamma}_{p}}{\dot{\gamma}_{p, c r}}\right)^{v+1}+\left(\frac{\sigma}{\sigma_{c r}}\right)^{\alpha+1}=1,
$$

where $\dot{\gamma}_{p, c r}=\dot{\gamma}_{p, c r}(0)$ is the critical wall shear rate (or velocity gradient), corresponding to $p_{f}=p_{0}$ or $\sigma=0 ; \sigma_{c r}$ - critical normal stress; $v$ is the exponent in law (1), while $\alpha=1 / k$, where $k$ is the exponent featuring in the nonlinear law of melt behavior under normal stresses

$$
\sigma=K_{\sigma} \cdot \varepsilon^{k}
$$


where $K_{\sigma}$ and $k$ are melt constants at temperature $T_{e}$, and $\varepsilon$-tensile strain under the action of stress $\sigma$. It should be noted that the $\sigma$ and $\varepsilon$ of the melt are defined by natural concepts (according to Hencky) and not by engineering concepts, being large deformations.

From relation (3) there results the critical shear rate in the case of normal stresses $\sigma=\sigma\left(p_{f}\right)$, due to the internal melt pressure, $p_{f}$,

$$
\dot{\gamma}_{p, c r}\left(p_{f}\right)=\dot{\gamma}_{p, c r}(0) \cdot\left[1-\left(\frac{\sigma\left(p_{f}\right)}{\sigma_{c r}}\right)^{\alpha+1}\right]^{\frac{1}{v}} .
$$

Generally, $\sigma\left(p_{f}\right) / \sigma_{c r}=p_{f} / p_{c r}$, where $p_{c r}$ is the critical internal pressure.

It is found that for $p_{f}>p_{0}$, one obtains $\sigma\left(p_{f}\right) / \sigma_{c r}>0$, so that, in general,

$$
\dot{\gamma}_{p, c r}\left(p_{f}\right)<\dot{\gamma}_{p, c r}(0) \text {. }
$$

Consequently, to have a maximum value of it, it is necessary for the normal stresses to relax completely before leaving the die.

It is useful for $\dot{\gamma}_{p, c r}\left(p_{f}\right)$ to be as high as possible because the critical output through the die depends on it.

The value of pressure $p_{f}$ at the die outlet decreases with an increase in the length of the die, $l_{f}$ (Figure 7b). For example, for a polypropylene melt at $T_{e}=230^{\circ} \mathrm{C}$, it was experimentally found that $p_{f}=0.053-0.302 \mathrm{MPa}[22]$.

For the die in Figure $7 b$ the critical mass output through the die has the expression

$$
G_{m, c r}=\rho(T) \cdot G_{c r},
$$

where $\rho(T)$ is the melt density at the extrusion temperature and $G_{c r}$, is the volumetric critical output

$$
G_{c r}=\frac{\pi}{2(2+1 / v)} \cdot d_{f} \cdot s_{f}^{2} \cdot \dot{\gamma}_{p, c r}\left(p_{f}\right)
$$

The maximum allowable output through the die (curve 5 in Figure 2) is calculated with the relationship,

$$
G_{a d, \max }=\frac{G_{c r}}{c_{n}}
$$

where $c_{n}>1$ is a safety coefficient in relation to the critical condition at the die wall and $G_{c r}$, is the critical output through the final zone of die (7).

By using relationship (8) one can draw the curve 5 in Figures 1 and 2.

For other curves, $(3 ; 4)$ in Figure 2 , one uses $\left(G_{m}-p_{e}\right)$ dependence accounting for the whole geometry of the flow channel through the die. 


\section{Some practical cases}

As to establish the working field of the extrusion die, the results obtained in papers [23, 24] have been used.

For three blown film dies with different geometry of the flow channels one has drawn the working fields [23-25] for the following polymers:

- polypropylene (PP)

- two types of high-density polyethylene (HDPE - 1 and HDPE - 2)

- ethylene vinyl acetate (EVA).

The viscous constants $\left(K_{\tau}\right.$ and $\left.v\right)$ and the critical shear rate $\left(\dot{\gamma}_{c r}\right)$ of the polymers have been written in Table 1. The critical shear rate increases with temperature increase.

The viscous constants $\left(K_{\tau}\right.$ and $\left.v\right)$ and the critical shear rate $\left(\dot{\gamma}_{c r}\right)$ of the polymers have been written in Table 1. The critical shear rate increases with temperature increase.

Table 1. Viscous and critical elastic properties of the polymers

\begin{tabular}{|c|c|c|c|}
\hline$T\left[{ }^{\circ} \mathrm{C}\right]$ & $\mathrm{K}_{\tau}\left[\mathrm{Pa} \cdot \mathrm{s}^{\mathrm{v}}\right]$ & $v$ & $\dot{\gamma}_{c r}\left\lfloor\mathrm{~s}^{-1}\right\rfloor$ \\
\hline \multicolumn{4}{|c|}{ PP } \\
\hline 200 & $2.18 \times 10^{4}$ & 0.25 & 420 \\
\hline 210 & $2.03 \times 10^{4}$ & 0.25 & 505 \\
\hline 220 & $1.885 \times 10^{4}$ & 0.25 & 565 \\
\hline 240 & $1.60 \times 10^{4}$ & 0.25 & 954 \\
\hline \multicolumn{4}{|c|}{ HDPE - 1} \\
\hline 180 & $1.39 \times 10^{4}$ & 0.52 & 310 \\
\hline 200 & $1.09 \times 10^{4}$ & 0.46 & 465 \\
\hline 220 & $1.01 \times 10^{4}$ & 0.33 & 635 \\
\hline \multicolumn{4}{|c|}{ HDPE - 2} \\
\hline 180 & $1.53 \times 10^{4}$ & 0.51 & 295 \\
\hline 200 & $1.45 \times 10^{4}$ & 0.42 & 435 \\
\hline 220 & $1.27 \times 10^{4}$ & 0.33 & 595 \\
\hline \multicolumn{4}{|c|}{ EVA (12\% VA) } \\
\hline 120 & $3.8 \times 10^{4}$ & 0.38 & 187 \\
\hline 150 & $3.4 \times 10^{4}$ & 0.35 & 490 \\
\hline 240 & $1.53 \times 10^{4}$ & 0.33 & 1400 \\
\hline
\end{tabular}

The calculated output of polypropylene blown film is from extrusion machines built in Romania. The execution project was made at Polytechnics University of Bucharest (Project advisor V.V. Jinescu) and implemented by Sibiu Mechanical Factory. In general, the pressure drop along the extrusion die depends on the geometry of the channel, on the rheological behavior of the polymer melt, on the nozzle entry effect and the elastic effects and the sliding of the melt on the wall.

The extrusion die in Figure 8, attached to an extruder with diameter $D=60 \mathrm{~mm}$, has the die diameter $d_{f}=200 \mathrm{~mm}$ and a die gap thickness of $s_{f}=0.55$ and $0.65 \mathrm{~mm}$. The working fields for the two different geometries of the die, in the manufacture of polypropylene blown films are shown in Figure $8 \mathrm{~b}$ and c. A gap increased from $0.55 \mathrm{~mm}$ to $0.65 \mathrm{~mm}$ determined a shift of the curve for the maximum allowable output to higher values, because according to relations (7) and (8) $G_{a d, \max } \sim s_{f}^{2}$.

On the extrusion die in Figure $9 a$, provided with spider mandrel, a rather narrow working field was obtained when processing high density polyethylene (HDPE - 2) type 2 (Figure 9c).

The processing of high-density polyethylene (HDPE - 1) resulted in the working field in Figure 9, $b$, with a wider working field than in Figure $9 c$ corresponding to HPDE - 2. 

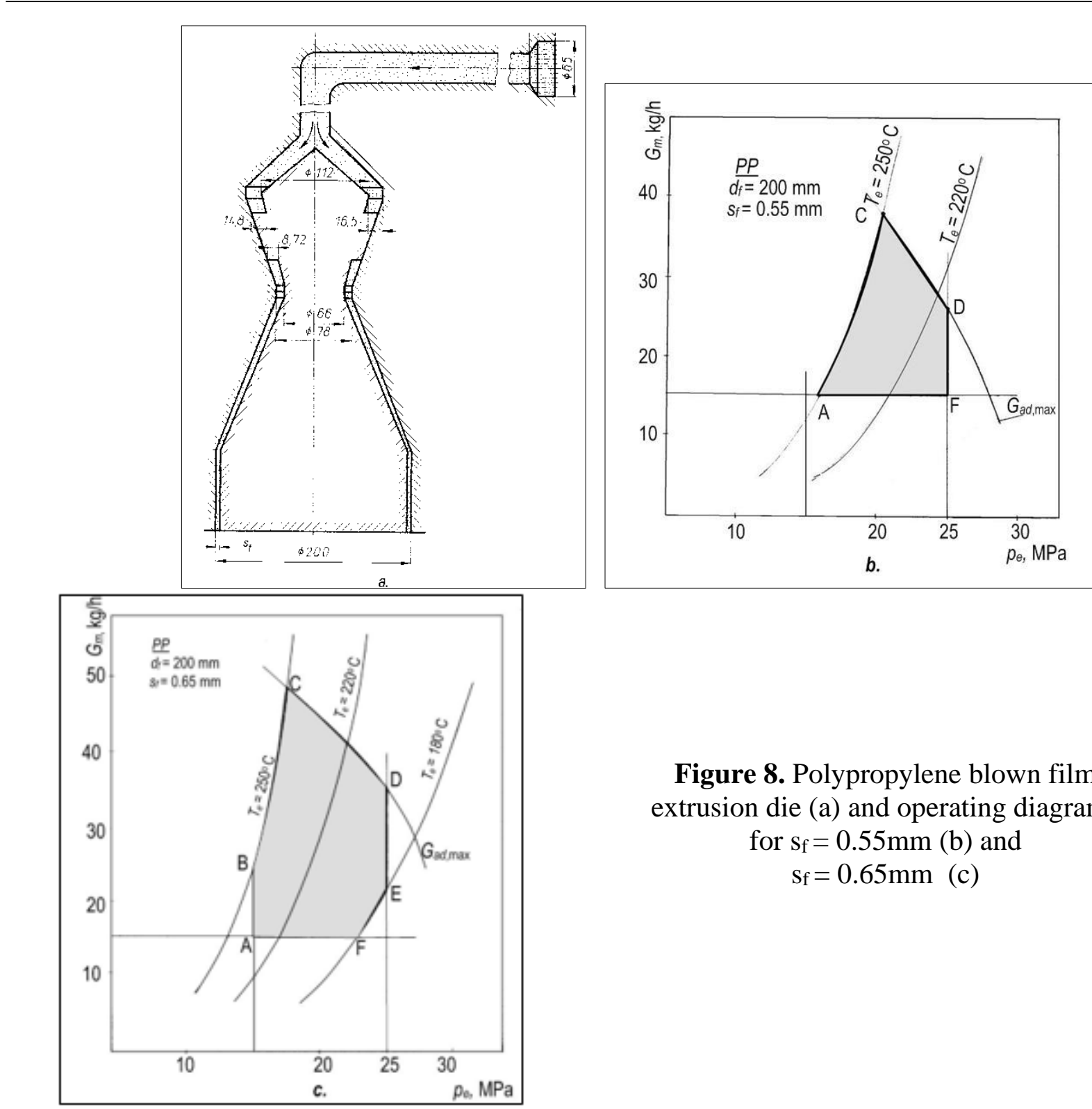

Figure 8. Polypropylene blown film extrusion die (a) and operating diagrams for $\mathrm{s}_{\mathrm{f}}=0.55 \mathrm{~mm}(\mathrm{~b})$ and $\mathrm{s}_{\mathrm{f}}=0.65 \mathrm{~mm} \quad(\mathrm{c})$
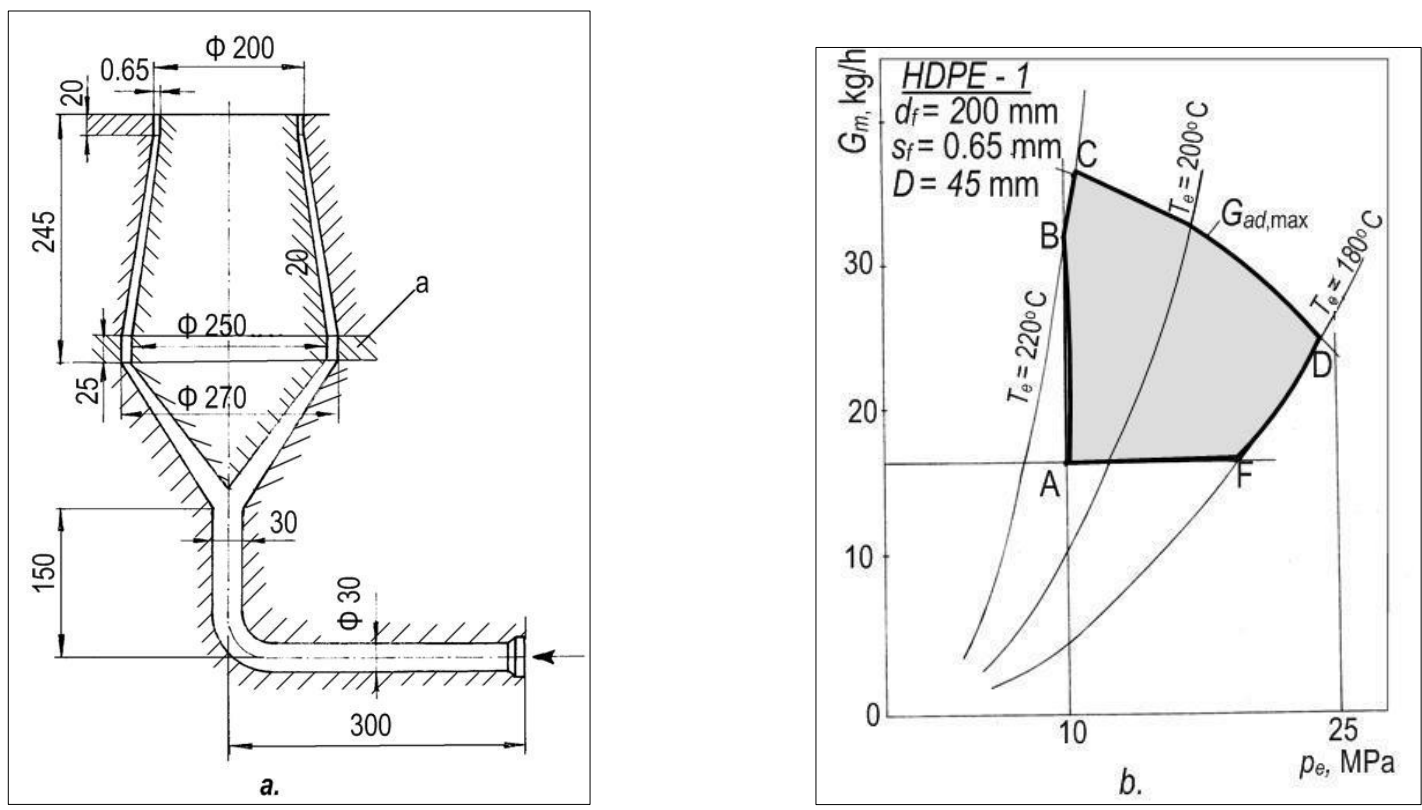


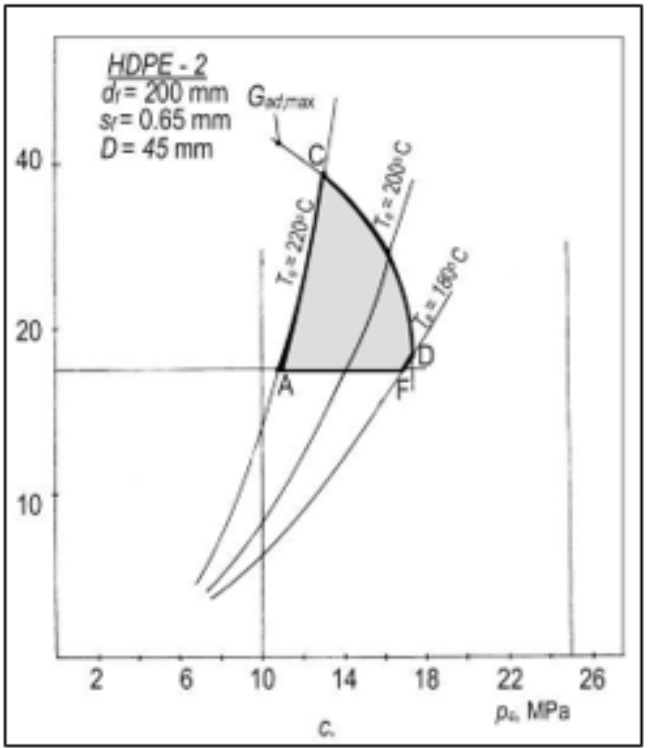

Figure 9. Extrusion die for blown film attached to an extruder with diameter $D=45 \mathrm{~mm}$ (a); working field of extrusion die for

HDPE - 1 (b) and

HDPE - 2 (c), respectively

When processing low density polyethylene (LDPE) on an extruder with $D=60 \mathrm{~mm}$ equipped with the extrusion die in Figure 10a, one obtained the working field in Figure 10b.
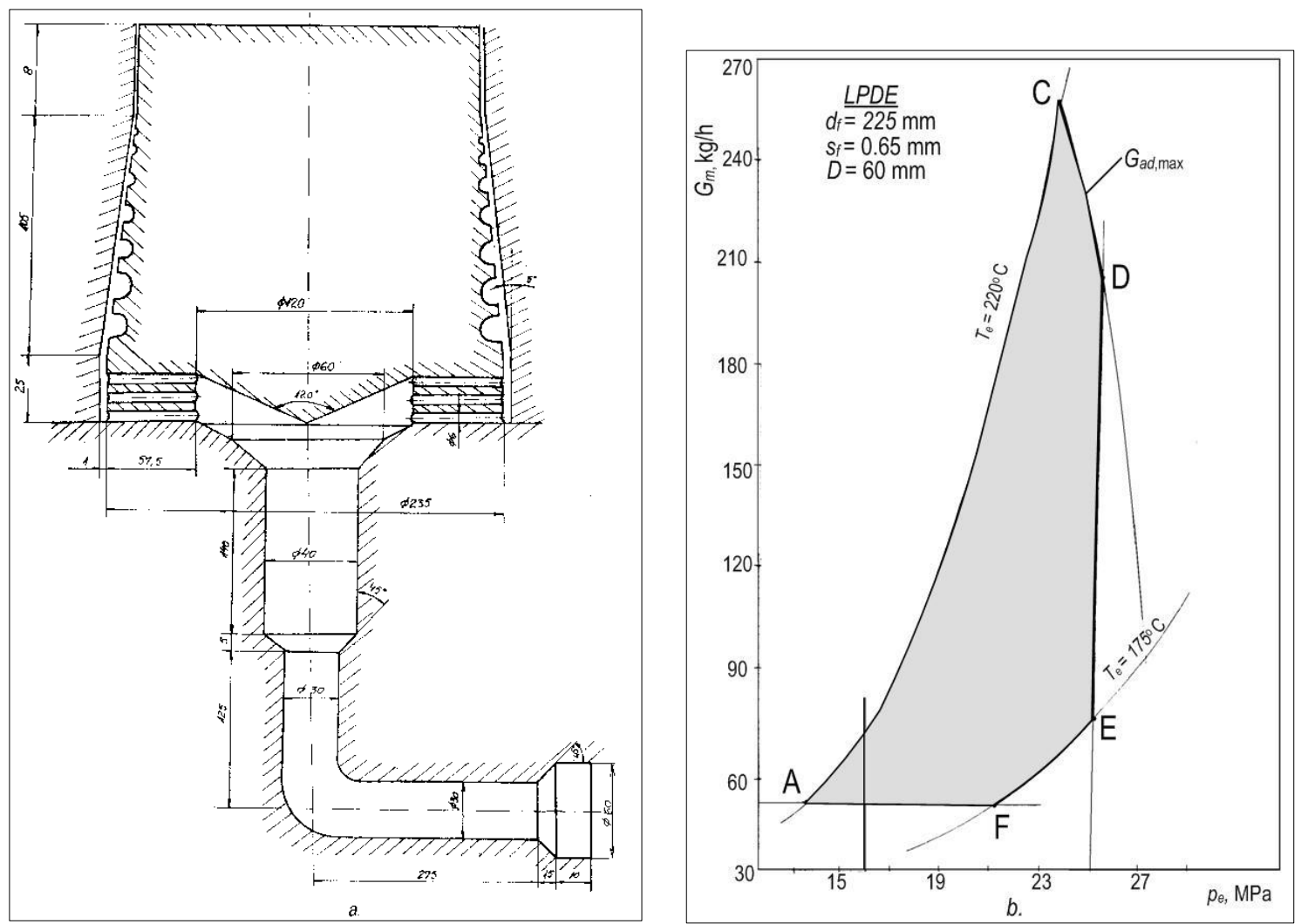

Figure 10. Extrusion die for blown film attached to an extruder with $D=60 \mathrm{~mm}$ (a) working field in processing low density polyethylene (LDPE) (b)

In case of the extrusion die in Figure 11a, in processing low density polyethylene (LPDE) one obtained the relatively narrow working field in Figure 11b. In processing high density polyethylene (HPDE -1) one obtained the operation range in Figure 11c. 
Figure 11. Extrusion die for blown film attached to an extruder with $D=60 \mathrm{~mm}$ (a) working field when processing LPDE (b) and HDPE - 1 (c)

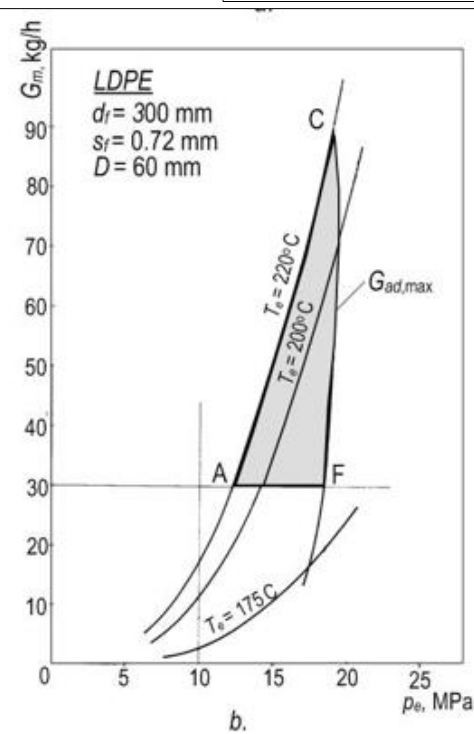

When processing ethylene vinyl acetate (EVA) as a blown film on the extrusion die in Figure 12a, the working field shown in Figure 12b, was obtained.
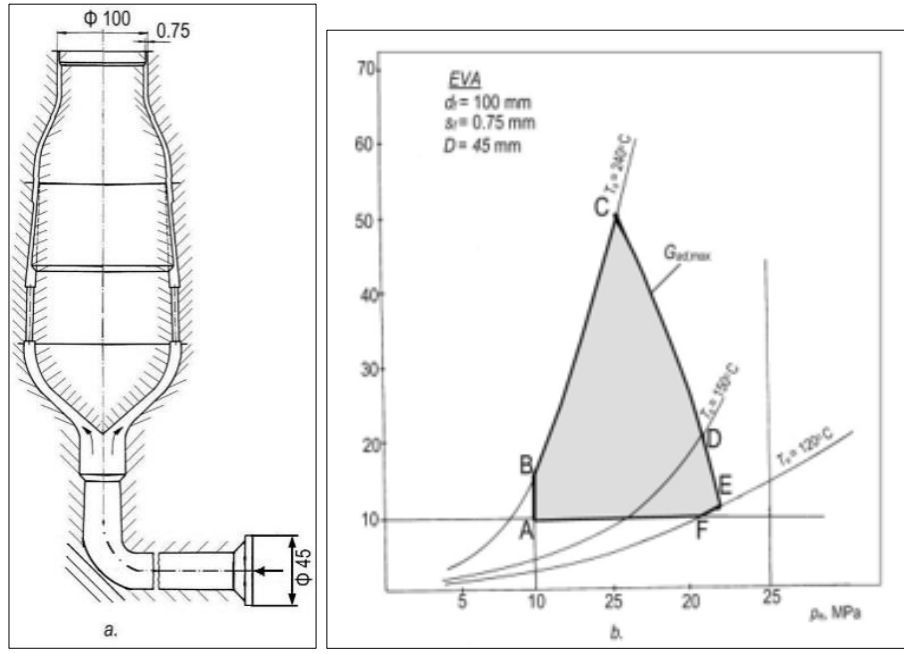

Figure 12. Extruder die for blown film attached to an extruder with diameter $D=45 \mathrm{~mm}$ (a) working field when processing ethylene vinyl acetate (EVA) (b) 
In general, to extend the working fields to higher output values, it is necessary to move vertically the maximum allowable output curve $G_{a d \text {, max }}$ This is possible, for example, by increasing $\dot{\gamma}_{c r}\left(p_{f}\right)$ and / or reducing the safety coefficient $c_{n}$ to values close to 1.2 .

From the analysis of the results obtained, represented in Figures 8 - 12, one can identify the influence of the following parameters upon the shape and extension of the working field of the extrusion die:

- nature of processed polymeric material, individualized by the viscous and elastic behavior of its melt

- extreme processing temperatures $\left(T_{\min } ; T_{\max }\right)$;

- type of extrusion die

- geometry of the channel through which the polymeric melt flows, especially in the final zone (nozzle), before leaving the extrusion die

- restrictions imposed for product quality and attenuation, until disappearance, of some effects of the elastic behavior of the polymer melt.

The operating point, the intersection of the functional characteristic of the extrusion die at the processing temperature with the functional characteristic of the screw, depends essentially on the:

-processing temperature

-screw velocity.

\section{Sequence of calculations for finalizing the melt path through the extrusion die}

The practical solution of the problem of maximum output at an appropriate quality of the extruded product, especially for complex cross section profiles can be done, at present, in the following stages, which may improve, in some cases, the proposed calculation method:

- one designs of the melt path through the extrusion die (the die profile)

- one draws the operation diagram (Figure 1) of the extrusion die (zero order approximation)

- one traces the functional characteristics of the screw (Figure 4) and the functional characteristics of the extrusion die (Figure 5)

- one establishes the effective output based on the intersection of the functional characteristics of the screw and the extrusion die (Figure 5)

- one makes a detailed analysis (for example, by the finite element method, CAD etc.) of the geometry of the extrusion die channels through which the melt flows (improvement in the velocity distribution at the die exit by flow simulation as to achieve a uniform melt flow in all sections)

- one analyzes the heat transfer between the melt and the extrusion die walls and the evaluation of the temperature profile across the thickness of the melt layer in the channel

- one corrects (adjusts) the sequence of channels in the extrusion die

- one recalculates and retraces the working field of the extrusion die (first order approximation), the operating characteristics of the extrusion die and one determines the working point and consequently, the output

- if the difference between the outputs of the two approximations (zero and one) is relatively large, we move to the second order approximation and so on. In successive stages, the profile of the extrusion die flow zones is optimized.

\section{Conclusions}

The working field of the extrusion die was delimited in the output - pressure diagram of the extrusion die inlet $\left(\mathrm{G}_{\mathrm{m}}-\mathrm{p}_{\mathrm{e}}\right)$ by resorting to an analysis of the flow through the extrusion die, by considering the regime parameters, the rheological behavior of the polymer melts and the influence of its elastic behavior on the quality of the extruded product,

The working field thus obtained was adjusted by considering the flow limitations imposed by the screw-cylinder subassembly regarding: -the minimum output corresponding to the screw diameter; - the 
maximum output at which the heating system on the cylinder (and possibly inside the screw) can ensure the intended extrusion temperature.

The interdependence between the critical shear rate and the normal internal melting stress at the die outlet was highlighted.

Finally, there were drawn out the working fields of several extrusion dies for polyethylene (HDPE), polypropylene (PP) and ethylene vinyl acetate (EVA) blown films.

One has detected the dependence of the extrusion die dimensions and working field extension on the rheological behavior of the polymer and on the geometry of the path through which the viscoelastic polymer melt flows. By applying the results obtained in this paper, the quality of the products and their strength are improved, which has the effect of reducing the risk of premature damage.

\section{References}

1.BERNHARDT E.C., „Processing of Thermoplastic Materials”, Van Nostrand Reinhold Company, New York, 1959.

2.McKELVEY J.M., „Polymer Processing”, John Wiley and Sons, New York, 1962.

3.TADMOR Z., KLEIN I., „Engineering Principles of Plasticating Extrusion”, Van Nostrand Reinholdt, New York, 1970.

4.TADMOR Z., GOGOS C.G., „Principles of Polymer Processing”, John Wiley, New York, 1979.

5.MARTELLI F.G., "Twin-screw extruders: a basic understanding", Van Nostrand Reinhold Company, New York, 1986.

6.RAUWENDAAL CH., "Polymer Extrusion”, Hanser Publishers, Münich-Vienna-New York, 1986. 7.CRAWFORD R.J., "Plastics Engineering", $2^{\text {nd }}$ Edition, Pergamon Press, Oxford, 1987.

8.HANSEN F., KNAPPE W., POTENTE H., "Handbuch der Kunststoff - Extrusionstechnik", vol. 1+2, Hanser Verlag, München, 1989.

9.WHITE J.L., “Twin Screw Extrusion”, Hanser Verlag, München, 1990.

10.HANSEN F., KNAPPE W., POTENTE H., "Plastics Extrusion Technology”, Hanser Publishers, Munich Vienna New York, 1988.

11.STEVENS M.J., COVAS J.A., „Extruders Principles and Operation”, Chapman\&Hall, 1995.

12.JINESCU, C.V., "Determination of the friction coefficient between the polymeric granular material and the metallic surfaces of the grooves specific to extruders' feeding zones", Polytechnic University Bucharest Bulletin, series D, vol. 71, nr. 1, 2009, p. 57-64.

13.JINESCU V.V., "Einige Wege zur Vergrösserung des Durchsatzes der Extrudiermaschinen", Kautschuk Gummi Kunststoffe, 47, nr. 11, 1994, p. 828.

14.JINESCU C.V., "Experimental determination of the flowrate coefficient required to calculate the flowrate in the feeding zone of a single screw extruder", Mater. Plast., 46(3), 2009, 279-283.

15.JINESCU C. V., "The optimisation of the Maddock \& Egan thermomechanical homogeneisation zones", Mater. Plast., 45(1), 2008, 20-22.

16.KLASON C., JINESCU V.V., POŞTOACĂ I., „A Network Analysis of a Screw Mixing Zone”, Int. Polymer Processing, X, nr. 1, 2000, p. 3.

17.KLASON C., JINESCU V.V., POŞTOACĂ I., "Pressure Variation by Dispersive Mixers in Plasticating Extrusion”, Kautschuk Gummi Kunststoffe, 52, 1999, p. 501.

18.JINESCU C.V., TEODORESCU N., JINESCU V.V., "The variation of temperature along the screw's channel depth at the polymeric materials extrusion”, Mater. Plast., 39(3), 2002, 153-159.

19.JINESCU V.V., "The influence of rhelogical behaviour on the extruder die performances",

Polymer Processing Society IX, Annual Meeting, Manchester 5-8 ${ }^{\text {th }}$, April 1993.

20.INN Y.W., FISHER R.J., SHAW M.T., "Visual Observation of development of sharkskin melt fracture in prolybatadien extrusion", Reologica Acta, 37, 1998, p. 573-582.

21.JINESCU V.V., "Principiul energiei critice şi aplicaţiile sale", Editura Academiei Române, Bucureşti, 2005. 
22.CHAN T.W., PAN B., YUAN H, Rheologica Acta, 29, 1990, p. 60.

23.JINESCU V.V., TUHAR E., “Metodă pentru calculul capetelor de extrudere I”, Mater. Plast., 13(1), 1976, 49-53.

24.JINESCU V.V., TUHAR E., "Metodă pentru calculul capetelor de extrudere II", Mater. Plast., 13(3), 1976, 179-183.

25.ANSARI M., ALABBAS A., HATZIKIRIAKOS S.G., MITSOULIS E., „Entry Flow of Polyethylene Melts in Tapered Dies", Int. Polymer Processing, nr. 4, 2010, p. 287 - 295.

Manuscript received: 31.05 .2021 